\title{
Films Based on Blends of Polyvinyl Alcohol and Microbial Hyaluronic Acid
}

\author{
Nicole Caldas Pan ${ }^{1}$ \\ https://orcid.org/0000-0001-6878-5623
}

Gabrielly Terassi Bersaneti ${ }^{1}$

https://orcid.org/0000-0002-6264-8844

\author{
Suzana Mali ${ }^{1 *}$ \\ https://orcid.org/0000-0003-4601-1568
}

\section{Maria Antonia Pedrine Colabone Celligoi ${ }^{1}$ \\ https://orcid.org/0000-0003-2217-8937}

1State University of Londrina, CCE, Department of Biochemistry and Biotechnology, Londrina, Paraná, Brazil.

Received: 2019.07.01; Accepted: 2020.03.17.

*Correspondence: smali@uel.br; Tel.: +55-43-3371-4270 (S.M.)

\section{HIGHLIGHTS}

- Hyaluronic acid (HA) was obtained by fermentation in a low cost medium.

- HA addition of 5 and $10 \%$ improved the polyvinyl alcohol (PVA) films properties.

- Addition of $10 \% \mathrm{HA}$ improved films thermal stability and water vapor permeability.

- Films based on PVA and HA are promising material to biomedical application.

Abstract: The aims of this work were to produce hyaluronic acid (HA) by Streptococcus zooepidemicus ATCC 39920 in a low cost sugarcane molasses fermentation medium and to employ the produced HA to obtain films blends based on polyvinyl alcohol (PVA). The films were produced using solution casting method and they were characterized according to their microstructure, mechanical and barrier properties. HA was added in different concentrations $(0,5,10$ and $15 \%(\mathrm{w} / \mathrm{w}))$, and glycerol was used as a plasticizer $(25 \mathrm{~g} / 100$ $\mathrm{g}$ solids). All formulations resulted in easily manipulated films with good appearance. The addition of HA on PVA films increased their thermal stability, solubility, swelling index, water vapor permeability and elongation. Microbial HA sample combined with PVA showed to be a promising material to biomedical application, and an addition between 5 and 10\% (w/w) was sufficient to improve PVA films properties.

Keywords: Microbial hyaluronic acid; polyvinyl alcohol; barrier properties; mechanical properties.

\section{INTRODUCTION}

Hyaluronic acid $(\mathrm{HA})$ is a non-sulfated linear glycosaminoglycan that consists of repeating disaccharide units of $\beta(1 \rightarrow 4)$-glucuronic acid (GlcUA) and $\beta(1 \rightarrow 3)$-N-acetylglucosamine (GlcNAc) [1]. It is also a major extracellular matrix component that is found in vertebrates [2]. Its capacity for holding water and its high viscoelasticity, as well as its biocompatibility and biodegradability, make HA a suitable biomaterial for use in several areas ranging from tissue engineering to cosmetic application [3-5]. 
Traditionally, native HA was extracted from animal tissues, most often from rooster comb. More recently, the polymer has been produced by the fermentation of Streptococci, thereby eliminating the possibility of inter-species disease transfer [6,7]. In addition, the use of low-cost renewable resources and agro-industrial by-products as fermentation media contributes to making microbial HA production economically feasible [810].

According to Mogoşanu and Grumezescu [11], there are several natural and synthetic polymers that are used as dressings for regenerating and repairing dermal and epidermal tissues during the wound healing process. Law and coauthors [12] reported that HA is a natural polymer with the potential to be used for this purpose; however, it is expensive, as the value of HA products and their derivatives range from US $\$ 2,000$ to $\$ 60,000 \mathrm{~kg}^{-1}[13]$.

Due to its high cost, HA can be combined with different polymers to reduce its price and improve its physicochemical and biological properties. The incorporation of HA on films based on blends to wound dressing application is justified due to the polymer improve the proliferation, differentiation and migration of cells during the regeneration and healing of tissues [14-17]. The blend system of polyvinyl alcohol (PVA) and HA has been reported to be a promising material for biomedical application $[16,18,19]$.

On an industrial scale, PVA is obtained by partial or complete hydrolysis of polyvinyl acetate to remove the acetate groups, with the partially hydrolysed grades containing residual acetate groups [20]. PVA is a synthetic hydrophilic polymer that is non-toxic, non-carcinogenic, biocompatible, biodegradable and bioadhesive [16,21]. For this reason, PVA films are of particular interest for application in wound healing, being an ideal polymer to be combined with HA.

Previous studies have used commercial HA for production of PVA-HA gels [18,22,23], cryogels membranes [16,24,25] and solutions [26]. Ding and coauthors [27] obtained a multi-layered hydrogel film system based on hyaluronic acid-cysteamine (HA-Cym) and PVA. Kuchaiyaphum and coauthors [25] produced PVA-HA cryogel by repeated freezing and thawing method as the purpose to remove the effect of chemical cross-linkers.

In our work, we employed HA produced by Streptococcus zooepidemicus ATCC 39920 in a low-cost sugarcane molasses fermentation medium to produce a blend with polyvinyl alcohol. The blend resulted in biodegradable and biocompatible films, which were characterized according to their microstructure, mechanical, thermal and barrier properties.

\section{MATERIALS AND METHODS}

\section{Materials}

The polyvinyl alcohol was provided by Sekisui Specialty Chemicals (Dallas, TX, USA) as Selvol TM 325 (degree of hydrolysis $=98.4 \%$ and $85-124 \mathrm{KDa}$ molecular weight). Glycerol was purchased from Synth (Labsynth, São Paulo, Brazil). Streptococcus zooepidemicus ATCC 39920 (for HA production) was obtained from the Brazilian Collection of Environmental and Industrial Microorganisms (CBMAI). The sugarcane molasses fermentation medium was obtained from the Alltech group (São Pedro do Ivaí, PR, Brazil).

\section{Production of Microbial HA}

The HA production and purification were conducted based on the method described by Pan and coauthors [9]. Batch fermentation in a bioreactor (Tecnal, Piracicaba, SP, Brazil) was conducted in a fermentation medium containing clarified sugarcane molasses with $85.35 \mathrm{~g} \mathrm{~L}^{-1}$ total sugar content, $50 \mathrm{~g} \mathrm{~L}^{-1}$ yeast extract, $2.5 \mathrm{~g} \mathrm{~L}^{-1} \mathrm{~K}_{2} \mathrm{HPO}_{4}, 2.0 \mathrm{~g} \mathrm{~L}^{-1} \mathrm{NaCl}$ and $1.5 \mathrm{~g} \mathrm{~L}^{-1} \mathrm{MgSO}_{4}$ at $\mathrm{pH} 8.0$ for $24 \mathrm{~h}$. Cell-free supernatant was precipitated with ethanol at a 1.5:1.0 (v/v) ratio of ethanol:supernatant at $4{ }^{\circ} \mathrm{C}$ for $1 \mathrm{~h}$. The HA was redissolved in a $0.15 \mathrm{~mol} \mathrm{~L}^{-1} \mathrm{NaCl}$ solution. Three precipitations were performed to increase the HA purity. Trichloroacetic acid $(1 \% \mathrm{w} / \mathrm{w})$ was added until the $\mathrm{HA}$ solution reached $\mathrm{pH} 2.0$, and the solution was maintained for $1 \mathrm{~h}$ at $4{ }^{\circ} \mathrm{C}$. Next, the solution was centrifuged at $7744 \times \mathrm{g}$ at $4{ }^{\circ} \mathrm{C}$ for $30 \mathrm{~min}$. The supernatant was dialyzed for $48 \mathrm{~h}$ with six distilled water changes, and the frozen dialysis product was lyophilized. Sodium hyaluronate with a molecular weight of $1.5-1.8 \times 10^{6} \mathrm{Da}$ (Sigma-Aldrich) was used as the standard.

The HA homogeneity was determined by high performance steric exclusion chromatography (HPSEC) coupled with a refractive index (RI) detector, model RID 10A. The chromatography system consisted of an HPLC pump (Model Shimadzu-10 AD), a manual injection valve (Shimadzu) fitted with a 200- $\mu$ L loop and Ultrahydrogel columns $(7.8 \times 300 \mathrm{~mm})$ arranged in series with a different exclusion limit connected in order of decreasing pore size, $7 \times 10^{6}, 4 \times 10^{5}, 8 \times 10^{4}$ and $5 \times 10^{3} \mathrm{Da}$, corresponding to Ultrahydrogel (Waters) 2000, 500, 250 and $120 \mathrm{~nm}$, respectively. The mobile phase was $0.1 \mathrm{M} \mathrm{NaNO}_{3}$ with sodium azide $(0.03 \%$

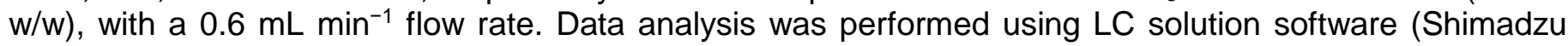


Corporation). A standard curve of dextran with molecular weights of 2000, 1400, 670, 500, 410, and $266 \mathrm{kDa}$ was used to determine the apparent molecular weight of the $\mathrm{HA}$, which was $1.35 \times 10^{6} \mathrm{Da}$.

\section{Film Production}

The films were prepared using PVA, microbial HA and glycerol (plasticizer). For each experiment, the films were prepared with a fixed concentration ( $2 \% \mathrm{w} / \mathrm{w}$ filmogenic solution) of solids (PVA $+\mathrm{HA})$ and a fixed glycerol concentration ( $25 \mathrm{~g} / 100 \mathrm{~g}$ solids). Four different HA levels were added to the filmogenic solutions: 0 , 5, 10 and 15\% w/w solids, and the resulting films were labelled PVA100, PVA95-HA5, PVA90-HA10 and PVA85-HA15, respectively. Minimum and maximum concentrations considered in this work were optimized in preliminary studies (not presented) after considering several ratios of PVA and HA to obtain films with good mechanical properties and easy to handle.

The films were prepared using solution casting method according to the formulations described in Table 1. PVA and glycerol were directly mixed with distilled water and maintained at $95^{\circ} \mathrm{C}$ for 30 min with manual shaking. After gelation, each PVA solution was cooled to nearly $70^{\circ} \mathrm{C}$ and mixed with the HA solution for 30 min. The filmogenic solutions were poured onto circular acrylic plates $\left(0.63 \mathrm{~g}\right.$ filmogenic solution $\left./ \mathrm{cm}^{2}\right)$ and dried at $30{ }^{\circ} \mathrm{C}$ in a ventilated oven, model TE-394-3 (Tecnal, Piracicaba, SP, Brazil) to a constant weight (approximately $30 \mathrm{~h}$ ). The resulting translucent films could be easily removed from the plate and were equilibrated at $25^{\circ} \mathrm{C}$ and a relative humidity $(\mathrm{RH})$ of $58 \%$ for $48 \mathrm{~h}$ before testing.

Table 1. Formulation employed to prepare $100 \mathrm{~g}$ of the filmogenic solutions.

\begin{tabular}{lcccc}
\multicolumn{1}{c}{ Formulations } & PVA $(\mathrm{g})$ & $\mathrm{HA}(\mathrm{g})$ & Glycerol $(\mathrm{g})$ & Water $(\mathrm{g})$ \\
\hline PVA100 film & 2.0 & 0 & 0.5 & 97.5 \\
PVA95-HA5 film & 1.9 & 0.1 & 0.5 & 97.5 \\
PVA90-HA10 film & 1.8 & 0.2 & 0.5 & 97.5 \\
PVA85-HA15 film & 1.7 & 0.3 & 0.5 & 97.5 \\
\hline
\end{tabular}

\section{Film Characterization}

\section{Thickness}

The film thickness was determined using a Mitutoyo manual micrometer (São Paulo - Brazil) with an accuracy of $\pm 1 \mu \mathrm{m}$ at 10 random positions on the film.

\section{Scanning Electron Microscopy (SEM)}

SEM analyses were performed using a JEOL JSPM 100 electron microscope (Japan). Film pieces were mounted on bronze stubs and then coated with a layer of gold $(40-50 \mathrm{~nm})$. All samples were examined using an accelerating voltage of $20 \mathrm{kV}$.

\section{Fourier Transform Infrared Spectroscopy (FT-IR)}

Pulverized and dried samples were mixed with potassium bromide and compressed into tablets. FT-IR analysis was performed using a Shimadzu-8400 FT-IR instrument (Japan). Measurements were performed in triplicate, and 100 scans were run in the spectral range of $4000-400 \mathrm{~cm}^{-1}$. The spectral resolution was 4 $\mathrm{cm}^{-1}$.

\section{Differential Scanning Calorimetry (DSC)}

The DSC analyses were performed on a Shimadzu DSC 60 (Japan) calorimeter. Approximately $3.0 \mathrm{mg}$ of each sample were placed in platinum containers. HA, PVA and film samples were heated from 10 to 300 ${ }^{\circ} \mathrm{C}$ at a heating rate of $5^{\circ} \mathrm{C} \mathrm{min}^{-1}$ in a helium atmosphere. An empty pan was used as a reference.

\section{Thermogravimetric Analysis (TGA)}

Thermogravimetric analysis (TGA 50, Shimadzu, Japan) was carried out in a nitrogenous atmosphere $\left(50 \mathrm{~mL} \mathrm{~min}^{-1}\right)$, and the samples (approximately $10 \mathrm{mg}$ ) were heated from 30 to $600^{\circ} \mathrm{C}\left(10^{\circ} \mathrm{C} \mathrm{min}{ }^{-1}\right)$. For each sample, the temperature of maximum degradation $\left(T_{\max }\right)$ and the temperature at which $10 \%$ weight loss occurred $\left(T_{90}\right)$ were determined. 


\section{Solubility}

The film solubility in water was measured as the percentage of dry matter of the film $\left(1 \mathrm{~cm}^{2}\right)$ solubilized during $24 \mathrm{~h}$ [28]. The initial dry matter $\left(W_{i}\right)$ was obtained after drying the film specimens in desiccators containing anhydrous calcium chloride for a week. The samples were weighed and immersed in $80 \mathrm{~mL}$ distilled water at $25^{\circ} \mathrm{C}$ with constant agitation for $24 \mathrm{~h}$. Film fraction not solubilized in water was separated by centrifugation and dried to determine the dry matter weight $\left(W_{f}\right)$. Tests were performed in triplicate. The solubility was determined from Solubility $(\%)=\left[\left(\mathrm{W}_{\mathrm{i}}-\mathrm{W}_{\mathrm{f}}\right) / \mathrm{W}_{\mathrm{i}}\right] \times 100$.

\section{Swelling Index (SI)}

The swelling index was determined in distilled water at $37^{\circ} \mathrm{C}$. Films were cut into pieces of approximately $1 \mathrm{~cm}^{2}$, placed in Petri dishes, left into an oven at $30^{\circ} \mathrm{C}$ for $6 \mathrm{~h}$ and weighed to determine the dry mass $\left(\mathrm{W}_{\mathrm{d}}\right)$. The dried samples were immediately immersed in distilled water, incubated at $37^{\circ} \mathrm{C}$ and weighed again (Ws) at specific interval times $(1,10,60$ and $120 \mathrm{~min})$. The swelling index was determined from $\mathrm{SI}(\%)=\left[\left(\mathrm{W}_{\mathrm{s}}-\right.\right.$ $\left.\left.\mathrm{W}_{\mathrm{d}}\right) / \mathrm{W}_{\mathrm{d}}\right] \times 100$.

\section{Water Vapor Permeability (WVP)}

WVP tests were conducted using the ASTM method E96 [29]. Each film sample was sealed over a circular opening of $0.00181 \mathrm{~m}^{2}$ in a permeation cell stored at $25^{\circ} \mathrm{C}$ in a desiccator. To maintain a $75 \%(\mathrm{w} / \mathrm{w})$ $\mathrm{RH}$ gradient across the film, anhydrous calcium chloride $(0 \% \mathrm{RH})$ was placed inside the cell, and a saturated sodium chloride solution $(75 \% \mathrm{RH})$ was used in the desiccator. After steady state conditions were reached (approximately $2 \mathrm{~h}$ ), the cell was weighed every $2 \mathrm{~h}$ for $48 \mathrm{~h}$. Changes in the cell weight were recorded and plotted as a function of time. The slope of each line was calculated by linear regression, and the water vapor transmission rate (WVTR) was calculated from the slope of the straight line $\left(\mathrm{g} \mathrm{s}^{-1}\right)$ divided by the transfer area $\left(\mathrm{m}^{2}\right)$. After the permeation tests, the film thickness was measured, and the WVP $\left(\mathrm{g} \mathrm{m}^{-1} \mathrm{~s}^{-1} \mathrm{~Pa}^{-1}\right)$ was calculated as $W V P=\left[W V T R / S\left(R_{1}-R_{2}\right)\right] d$, where $S$ is the saturation vapor pressure of water $(\mathrm{Pa})$ at the test temperature $\left(25^{\circ} \mathrm{C}\right) ; \mathrm{R}_{1}$ is the $\mathrm{RH}$ in the desiccator; $\mathrm{R}_{2}$ is the $\mathrm{RH}$ in the permeation cell; and $d$ is the film thickness $(m)$. Under these conditions, the driving force $\left[S\left(R_{1}-R_{2}\right)\right]$ was $1753.55 \mathrm{~Pa}$. All tests were conducted in duplicate.

\section{Mechanical Properties}

The mechanical properties were determined using an EMIC DL 2000 analyser (Brazil), according to the method established by ASTM D882-02 [30].

\section{Statistical Analysis}

Tukey's test ( $p \leq 0.05)$ was performed by the R Software [31] to compare means.

\section{RESULTS AND DISCUSSION}

In this study, we produced a high molecular weight HA from a fermentation process using $S$. zooepidemicus as an eco-friendly and renewable source alternative to the HA extracted from animal tissues. The lyophilized HA produced in this work could be easily incorporated into PVA solutions, resulting in homogeneous filmogenic solutions, which provided translucent films that could be easily manipulated (Figure 1). Due to the high molecular weight $\left(1.35 \times 10^{6} \mathrm{Da}\right)$ of the HA produced in this work, the polymer is suitable for use in biomedical applications such as wound healing [32], drug delivery [33], anti-adhesive barrier [25,34] and topical ocular therapy [35]. 


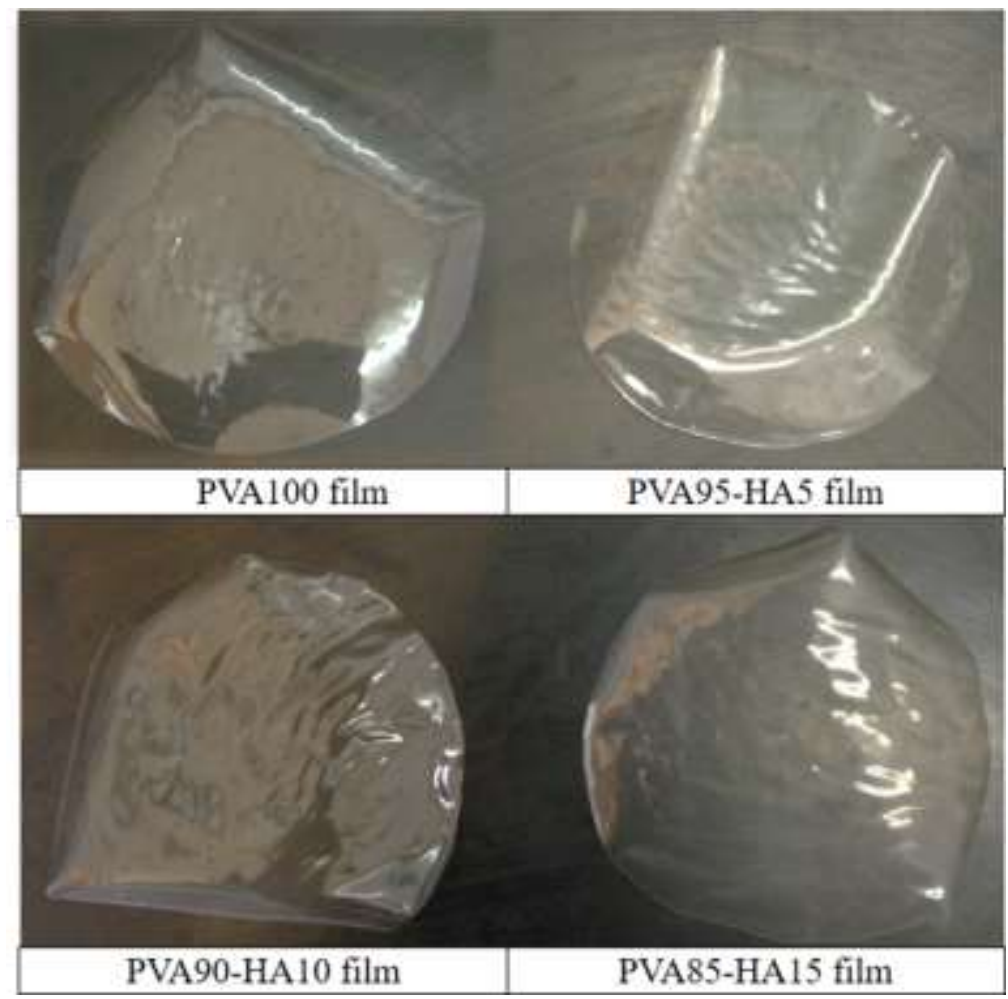

Figure 1. Appearance of films based on PVA and HA.

\section{Thickness and SEM}

The thicknesses of the films ranged from 0.20 to $0.22 \mu \mathrm{m}$, and the values did not differ significantly (Table 2) between the different formulations. The film surfaces were evaluated using SEM (Figure 2). All samples exhibited a homogeneous surface without phase separation, indicating a good interaction between the PVA and HA. The addition of HA resulted in rougher surfaces for the PVA95-HA5 and PVA90-HA10 films; however, the film with the higher HA content (PVA85-HA15) showed a smooth surface, similar to the film produced without HA (PVA100). The images of films cross-section with different HA concentrations did not show differences, all formulation resulted in compacted structures without pores or cracks (data not shown).

Table 2. Results of thickness, solubility and water vapor permeability (WVP) of films based on PVA and HA.

\begin{tabular}{lccc}
\hline \multicolumn{1}{c}{ Formulations } & Thickness $(\mu \mathrm{m})$ & Solubility $(\%)$ & WVP $\times 10^{11}(\mathrm{~g} / \mathrm{msPa})$ \\
\hline PVA100 film & $0.20 \pm 0.01^{\mathrm{a}}$ & $28.95 \pm 3.02^{\mathrm{d}}$ & $2.69 \pm 0.11^{\mathrm{b}}$ \\
PVA95-HA5 film & $0.22 \pm 0.01^{\mathrm{a}}$ & $36.81 \pm 1.42^{\mathrm{c}}$ & $3.85 \pm 0.74^{\mathrm{b}}$ \\
PVA90-HA10 film & $0.21 \pm 0.01^{\mathrm{a}}$ & $47.12 \pm 2.74^{\mathrm{b}}$ & $6.25 \pm 0.78^{\mathrm{a}}$ \\
PVA85-HA15 film & $0.21 \pm 0.02^{\mathrm{a}}$ & $57.76 \pm 2.27^{\mathrm{a}}$ & $5.90 \pm 0.47^{\mathrm{a}}$ \\
\hline
\end{tabular}

Results express in mean \pm standard deviation. Different letters in the same column indicate significant differences $(p \leq$ 0.05 ) according to the Tukey's test. 


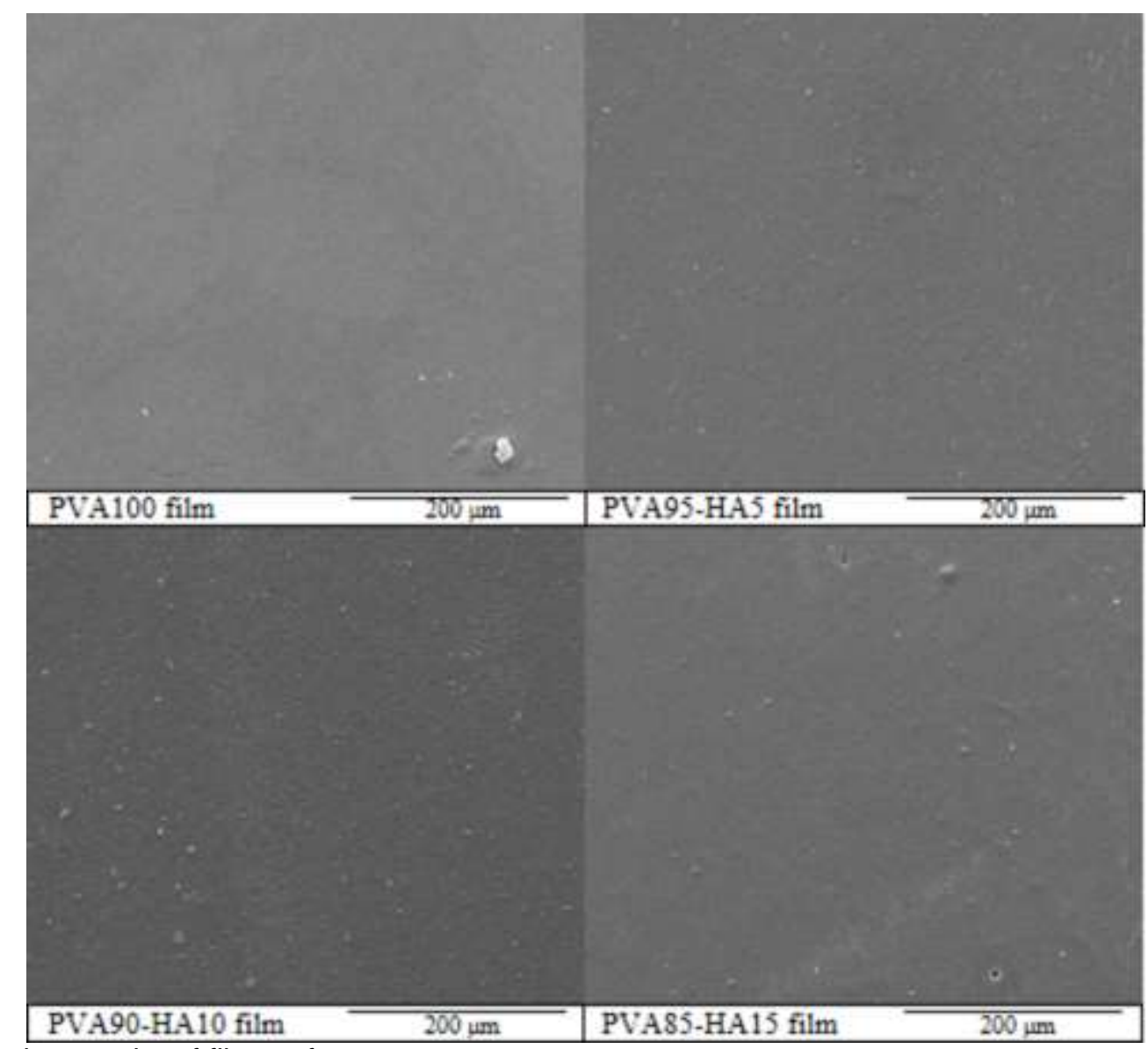

Figure 2. SEM micrographs of film surfaces.

\section{Fourier Transform Infrared Spectroscopy}

The FT-IR spectra of the PVA, HA and the films produced with PVA and the microbial HA sample are presented in Figure 3. The spectra of the HA sample produced by $S$. zooepidemicus was very close to the HA standard (Sigma-Aldrich).

In all samples, a strong band was observed near $3445 \mathrm{~cm}^{-1}$, which was related to the hydroxyl stretching vibrational modes of the OH groups presented on the HA, PVA and glycerol [36-38]. However, in the film samples, this band appeared to be less intense, which likely indicates a decrease in the free $\mathrm{OH}$ groups [39] that may be participating in hydrogen bonding between the polymer chains. The hydrogen bond formation between two different macromolecules competes with the hydrogen bond formation between molecules from the same polymer [15]. Due to a higher concentration of PVA in all film formulations, the PVA-PVA interaction might be more dominant than the PVA-HA interaction, which means that because the PVA concentration is higher, the chemical bonds that predominate in the polymer matrix are between the polymer molecules, therefore, the film spectra presented greater similarity to the PVA pure spectrum. In the samples containing $\mathrm{HA}$, the band near $3445 \mathrm{~cm}^{-1}$ can also be attributed to the $\mathrm{N}-\mathrm{H}$ stretching vibrations of the $\mathrm{N}$-acetyl side chain $[40,41]$.

The band approximately $2920 \mathrm{~cm}^{-1}$ appeared in both HA samples, but in the HA standard it was more intense than in the microbial HA sample, which corresponds to the $\mathrm{C}-\mathrm{H}$ stretching [42]. 


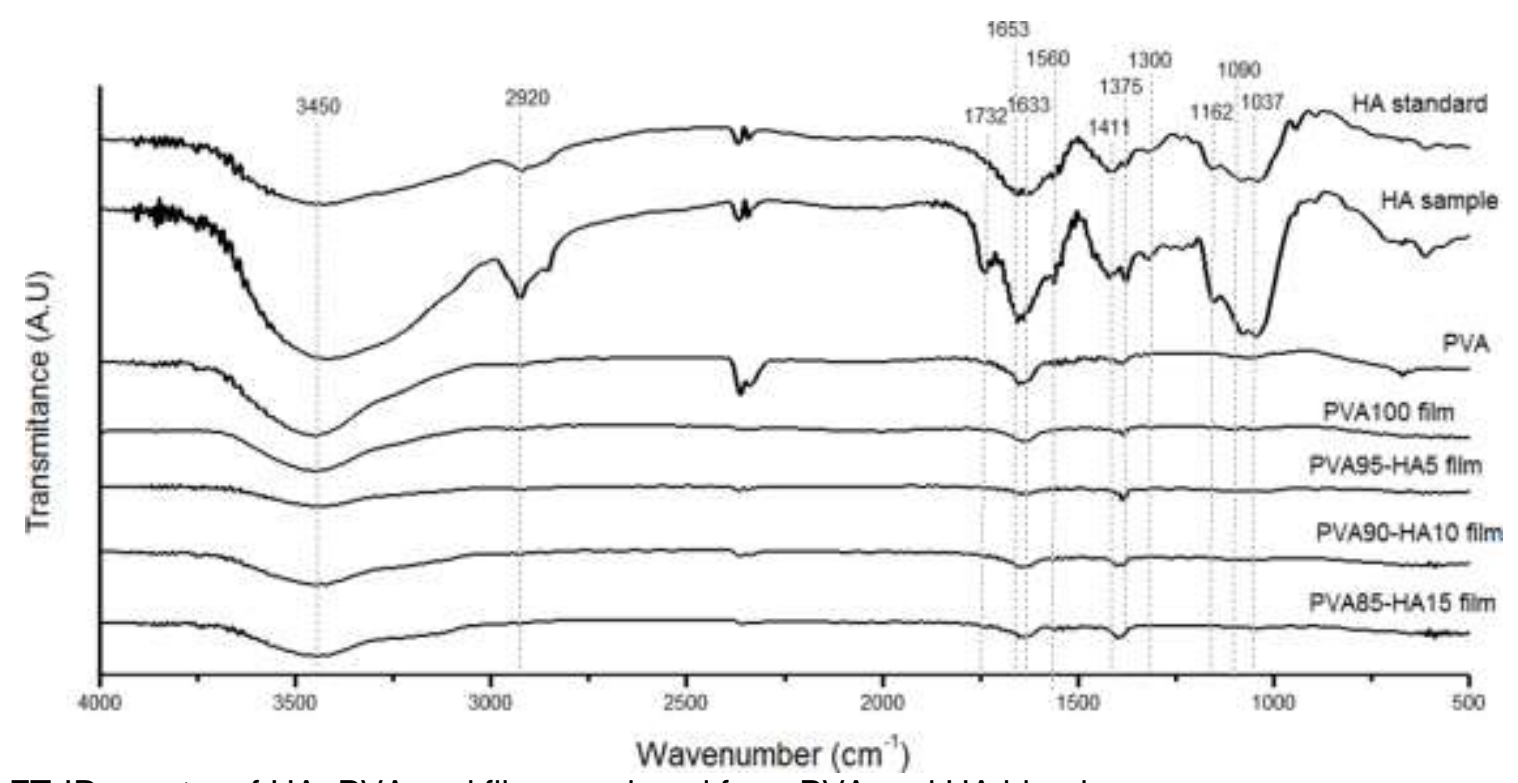

Figure 3. FT-IR spectra of HA, PVA and films produced from PVA and HA blends.

The bands between 1732 and $1560 \mathrm{~cm}^{-1}$ that appeared in both HA samples could be related to the superposition of the amide I and II bands in the HA, as well as the various carbonyl and carboxyl groups. Haxaire and coauthors [43] also observed an intense group of bands in this region in a commercial microbial $\mathrm{HA}$. The bands at 1633 and $1410 \mathrm{~cm}^{-1}$ were assigned to the asymmetric and symmetric stretching modes of the planar carboxyl groups in the HA, respectively.

In the PVA, the $1635 \mathrm{~cm}^{-1}$ band was attributed to the carbonyl functional groups since residual acetate groups remained after the PVA manufacturing due to the hydrolysis of the polyvinyl acetate [44]. The rise in intensity of these bands was observed with the increase of HA content in the PVA-HA films. Additionally, the film bands around $1635 \mathrm{~cm}^{-1}$ might be due to embedded water molecules [44]. A band at the $1375 \mathrm{~cm}^{-1}$ region was observed in all samples, which could be associated with the angular deformation of the $\mathrm{CH}$ and $\mathrm{CH}_{2}$ groups.

The amide I absorption peaks at $1653 \mathrm{~cm}^{-1}$, amide II peaks at $1560 \mathrm{~cm}^{-1}$ and amide III peaks at 1300 $\mathrm{cm}^{-1}$ are characteristic of the HA spectrum [41]. These bands were more intense in both HA spectra and less intense in the films containing HA. This indicates that interactions occurred between the film components. Bands in the $1200-950 \mathrm{~cm}^{-1}$ region were attributed to a C-O-C (O-bridge), a C-O (exocyclic), and a C-OH group and were more intense in the HA because these bands are typical of carbohydrates [45] and could be related to the disaccharide units of $\mathrm{HA}$.

\section{Thermogravimetric Analysis}

TGA curves for the HA, PVA and PVA-HA films are shown in Figure 4, and the $T_{\max }$ and $T_{90}$ for each sample are shown in Table 3. Microbial HA and HA standard samples showed two mass loss events: an initial loss at $70-100{ }^{\circ} \mathrm{C}$, possibly associated with the evaporation of water, and a second more important mass loss at $245{ }^{\circ} \mathrm{C}$ (HA standard) and $286{ }^{\circ} \mathrm{C}$ (microbial HA) (Table 3). Chen and Cheng [46] related a maximum degradation temperature of $290{ }^{\circ} \mathrm{C}$ for $\mathrm{HA}$ (average molecular weight of $1.78 \times 10^{6} \mathrm{Da}$ ) when it was obtained by fermenting Streptococcus zooepidemicus. Lewandowska and coauthors [47] suggested a partial breakage of the HA molecular structure in the range of $200^{\circ} \mathrm{C}$ and $300^{\circ} \mathrm{C}$. 

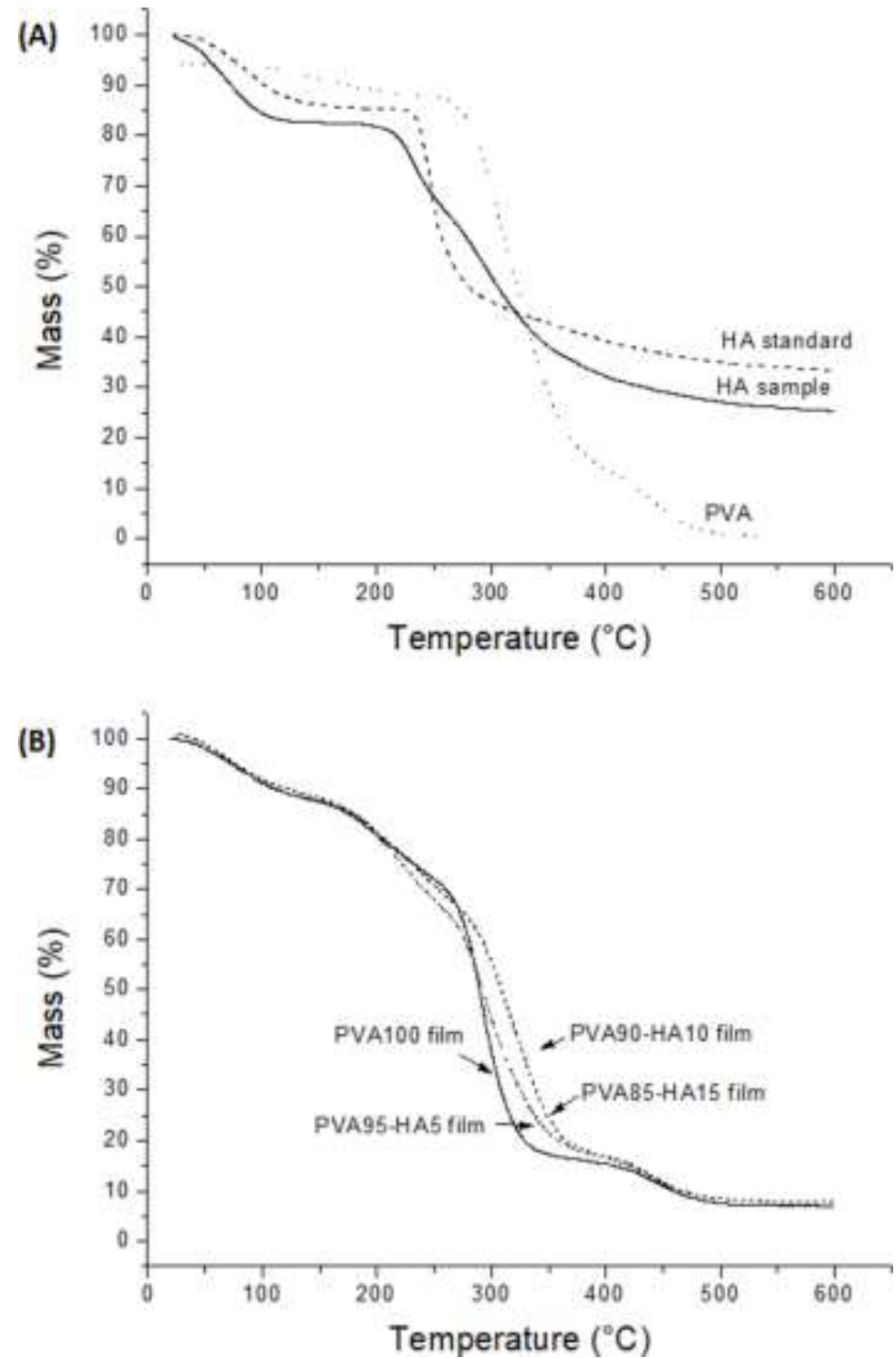

Figure 4. TGA thermograms of HA, PVA (A) and films produced from PVA and HA blend (B).

Pure PVA presented a more important weight loss event at $311^{\circ} \mathrm{C}$ and a second event at $450{ }^{\circ} \mathrm{C}$ (Table 3). According to Tubbs and Ting [48] and Sin and coauthors [49] thermal degradation of PVA occurs in two steps, an initial decomposition beginning at $200^{\circ} \mathrm{C}$, which is related to the dehydration of hydroxyl groups, followed by the formation of volatile organic compounds and the generation of conjugated unsaturated polyene structures. At higher temperatures, approximately $450{ }^{\circ} \mathrm{C}$, the second stage of degradation predominates by producing small quantities of hydrocarbon-related products such as alkenes, alkanes and aromatics.

The PVA film without the addition of HA (PVA100) presented a $\mathrm{T}_{90}$ of $110^{\circ} \mathrm{C}$, which is much lower than pure PVA, which has a $T_{90}$ of $278{ }^{\circ} \mathrm{C}$ (Table 3). This is explained by the thermal processing of the PVA in the presence of glycerol during film preparation. According to Jang and Lee [50], the introduction of glycerol as a plasticizer increases mobility between the PVA chains and decreases the crystallite region, which is associated with the thermal processing, and results in a decrease of thermal stability in the PVA. Othman and coauthors [51] also reported that PVA-starch-glycerol films had less thermal stability than pure PVA. Wang and coauthors [52] reported that when glycerol is added to an aqueous solution of PVA, the concentration of hydroxyl groups in the system increases, favouring the formation of new hydrogen bonds between the glycerol and PVA, replacing the interaction between the PVA chains, and decreasing the melting point and decomposition temperature of the PVA remarkably. 
Table 3. Results of TGA parameters.

\begin{tabular}{lcccc}
\hline \multirow{2}{*}{ Sample } & \multirow{2}{*}{$\mathrm{T}_{90 \%}\left({ }^{\circ} \mathrm{C}\right)$} & \multicolumn{3}{c}{$\mathrm{T}_{\max }\left({ }^{\circ} \mathrm{C}\right)$} \\
\cline { 3 - 5 } & 103 & $\mathrm{I}$ & $\mathrm{II}$ & $\mathrm{III}$ \\
\hline HA standard & 73 & 245 & & \\
HA sample & 278 & 311 & 450 & \\
PVA & 110 & 214 & 295 & 452 \\
PVA100 film & 110 & 218 & 305 & 454 \\
PVA95-HA5 film & 139 & 237 & 320 & 450 \\
PVA90-HA10 film & 120 & 220 & 321 & 452 \\
PVA85-HA15 film & & & & \\
\hline
\end{tabular}

The thermal degradation of the PVA100 film occurred in three steps at 214,295 and $452{ }^{\circ} \mathrm{C}$ (Table 3 ). As observed by Pereira and coauthors [53], the pure PVA film decomposed in four consecutive steps. The first step was due to thermal dehydration and the subsequent stages attributed to thermal decomposition of the anhydrous compound. The steps at $214^{\circ} \mathrm{C}$ and $295^{\circ} \mathrm{C}$ were due to dehydration accompanied by the formation of volatile products, and the last decomposition step at $452{ }^{\circ} \mathrm{C}$ was due to the degradation of the polyene residue from the synthesis of carbon and hydrocarbons [54]. The PVA90-HA10 film presented the higher values of $T_{90}$ and $T_{\max }$ (Table 3), indicating that this HA concentration (10\%) improves the thermal stability of the PVA films, possibly due to interactions between the PVA and HA. Sionkowska and coauthors [55] also observed an increase in thermal stability when HA was added into chitosan and collagen membranes. PVA95-HA5 film showed $T_{90}$ and $T_{\max }$ values that were very close to the PVA100 film (Table 3), possibly because this HA concentration was not enough to improve thermal stability in the PVA films. The PVA85-HA15 film had higher $T_{90}$ and $T_{\max }$ values than the PVA100 film, but these values were lower than those observed for the PVA90-HA10 film, suggesting that an HA addition of $10 \%(\mathrm{w} / \mathrm{w})$ results in a more organized structure, with a higher thermal stability.

\section{Differential Scanning Calorimetry}

The DSC thermograms of pure PVA (Fig. 5A) show an endothermic peak at $219^{\circ} \mathrm{C}$, related to the melting of the polymer. Maria and coauthors [56] reported temperatures between $180-190{ }^{\circ} \mathrm{C}$ for melting of PVA with a similar degree of hydrolysis. An exothermic sharp peak was observed at $239^{\circ} \mathrm{C}$ for the HA standard (Figure $5 \mathrm{~A})$, which could be associated with the thermal decomposition of the HA. This result was consistent with reports from other authors, who reported that exothermic peaks in HA DSC thermograms can be associated with the conversion of HA into a less-ordered state [57] and also to its thermal degradation $[57,58]$. The microbial HA did not have this exothermic peak.

As observed in the TGA results (Table 3 ), the $T_{\max }$ for the HA standard $\left(245^{\circ} \mathrm{C}\right.$ ) was lower than the $\mathrm{T}_{\max }$ of the microbial HA sample $\left(286^{\circ} \mathrm{C}\right)$, and it was possible that the decomposition of the microbial HA did not appear in the DSC thermograms. 

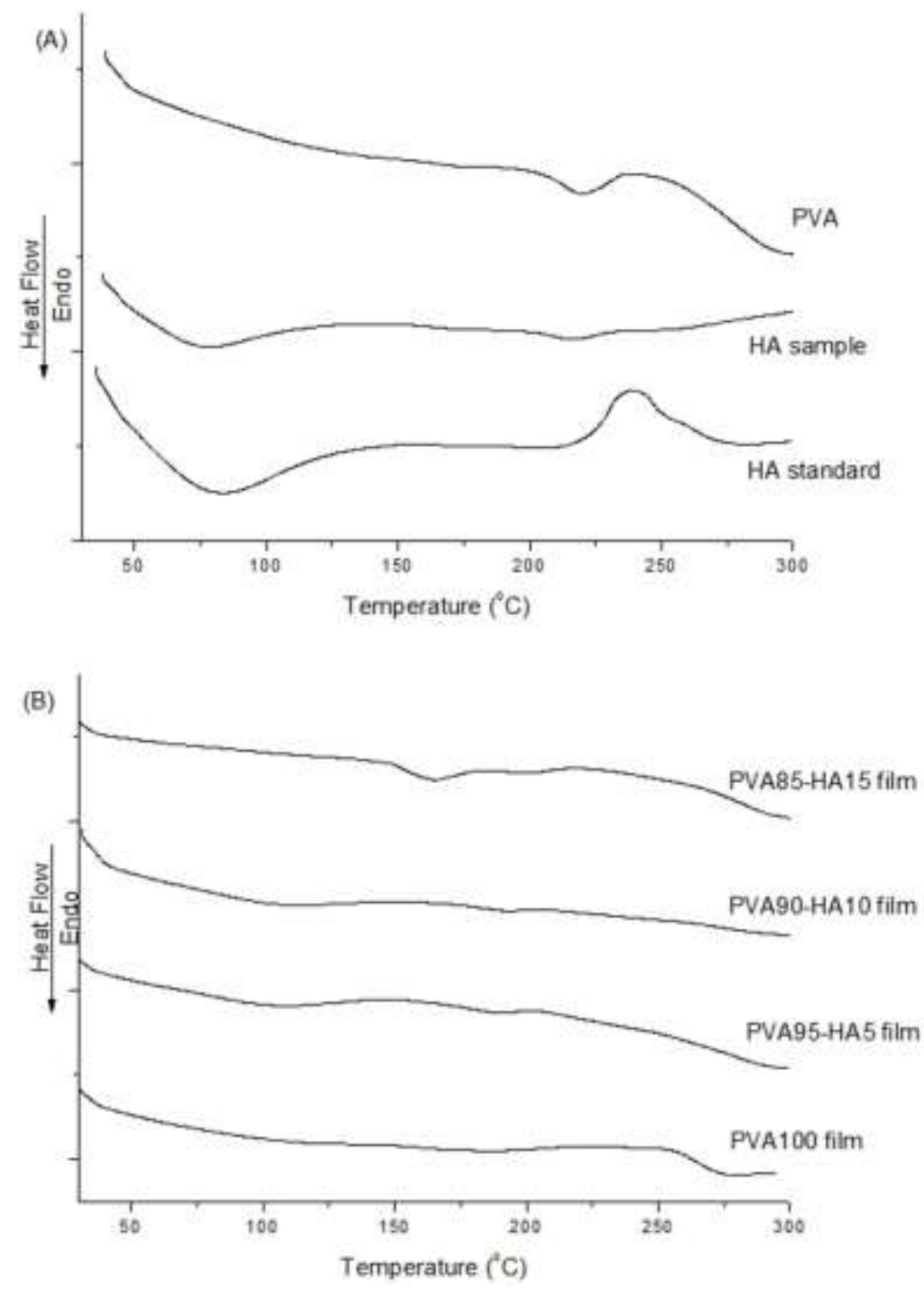

Figure 5. DSC thermograms of HA, PVA (A) and films produced from PVA and HA blends (B).

Thermograms of the films did not show any significant endo or exothermic events, with the exception of the PVA100 film, which had a discrete exothermic peak at $252^{\circ} \mathrm{C}$, and the PVA85-HA15 film, which had an endothermic peak at $163^{\circ} \mathrm{C}$ (Fig. 5B). During the thermal processing of the films, a new organization was established between the polymers chains, and according to Othman and coauthors [51], who studied PVAstarch films, interaction between the polymers could result in different melting and decomposition temperatures, which would indicate that there are interactions taking place.

\section{Solubility, swelling index and water vapor permeability}

The solubility of the films increased from $28.95 \%$ for the PVA100 film to $57.76 \%$ for the PVA85-HA15. The lower solubility of the pure film (PVA100) can be attributed to the formation of strong interactions between PVA chains due to the high degree of hydrolysis [59]. According to Jang and Lee [50], PVA with a higher degree of hydrolysis is less soluble in water because the large number of free hydroxyl groups increases the number of interactions (hydrogen bonds) that are carried out between the polymer chains, leaving fewer free hydroxyls to interact with the water.

When HA was added to the PVA films, the solubility significantly increased, and the PVA85-HA15 film was the most soluble, due to the higher HA concentration (Table 2). Adding HA molecules into the PVA film matrix may have affected the interactions between the PVA chains, resulting in more free hydroxyl groups in the PVA to interact with the water. Additionally, when the HA molecules were added, the concentration of hydroxyl groups in the system increased, favouring the interaction between HA and water by hydrogen bonding.

The swelling index $(\mathrm{SI})$ of the samples are displayed in Figure 6 . The SI significantly increased with the increase of time, and for all assay times, the SI were significantly higher for the PVA90-HA10 and PVA85- 
HA15 films (Fig. 6). The increase in the SI of the PVA films with the HA addition has been observed in previous works, and it is related to the high HA hydrophilicity [16,55]. These results were consistent with the solubility results.

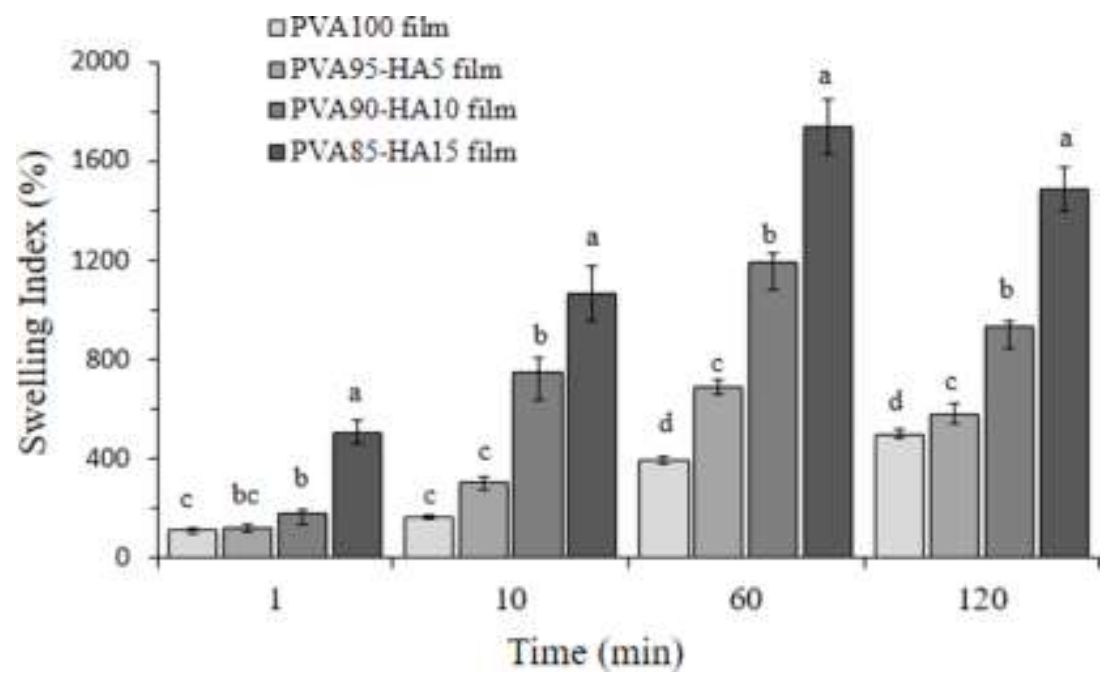

Figure 6. Swelling index of films produced from PVA and HA blends. Different letters in the same time indicate significant differences $(p \leq 0.05)$ according to the Tukey's test.

The swelling behaviour of scaffolds is critical for their practical use in biomedical applications [60] An increase in pore size due to swelling facilitates cell attachment and growth in a three-dimensional fashion [61]. Additionally, blood contains approximately $90 \%$ water, so films with good swelling properties can be used in the wound healing process because they can absorb a large amount of water and stop the bleeding [37]. Thus, considering solubility and SI values, possibly the films that had the best combination of results were those prepared 5 and $10 \%(\mathrm{w} / \mathrm{w}$ ) of HA, which had higher SI values and less than $50 \%$ of solubilization.

The water vapor permeability (WVP) of the films ranged from 2.69 to $5.90 \times 10^{-11}$ (Table 2), and these values were significantly influenced by the HA addition. Films with HA addition of 10 and $15 \%(\mathrm{w} / \mathrm{w})$ presented higher values of WVP, and these results were consistent with solubility values. Permeability can be defined as the product of diffusion and solubility, and the higher the solubility is, the higher the WVP [62]. Sgorla and coauthors [58] also verified a WPV increase when $10 \%(\mathrm{w} / \mathrm{w})$ of HA was added to ethylcellulose film, and these authors reported that $\mathrm{HA}$ is rich in hydroxyl groups that interact with water molecules to form hydrogen bonds. According to Xu and coauthors [63], WPV is required for proper wound dressing because controlling the water that is lost from an open wound is crucial for maintaining a wet environment during the woundrepairing process.

\section{Mechanical properties}

The mechanical properties of the films are presented in Table 4. The tensile strength of the films ranged from 8.48 MPa to $10.30 \mathrm{MPa}$, and this property was not significantly affected by adding HA. As HA possibly interferes with interactions between the PVA chains, it is best if the tensile strength of the film remains stable after HA is added. Young's modulus ranged from 25.27 to $31.87 \mathrm{MPa}$ (Table 4) and, similar to the tensile strength, was not significantly affected by adding HA. Unlike the tensile strength and Young's modulus, elongation was affected by addition of $\mathrm{HA}$ (Table 4). The maximum elongation value $(290.25 \%)$ was obtained for the PVA90-HA10 film, which contained 10\% (w/w) of HA, but when $15 \%(\mathrm{w} / \mathrm{w})$ of HA was added, the elongation significantly decreased. An increase in film elongation is important in wound dressing, as the dressing materials should remain intact when stretched [37]. Sionkowska and coauthors [55] observed that adding HA improves the elongation of chitosan-collagen blends due to the high hygroscopicity of the HA.

Table 4. Results of mechanical properties of films based on PVA and HA.

\begin{tabular}{lccc}
\hline \multicolumn{1}{c}{ Formulations } & Tensile Strength $(\mathrm{MPa})$ & Elongation $(\%)$ & Young's Modulus $(\mathrm{MPa})$ \\
\hline PVA100 film & $9.72 \pm 1.12^{\mathrm{a}}$ & $158.23 \pm 17.16^{\mathrm{c}}$ & $25.54 \pm 3.99^{\mathrm{a}}$ \\
PVA95-HA5 film & $8.48 \pm 1.60^{\mathrm{a}}$ & $170.86 \pm 13.24^{\mathrm{c}}$ & $31.87 \pm 5.33^{\mathrm{a}}$ \\
PVA90-HA10 film & $9.44 \pm 0.62^{\mathrm{a}}$ & $290.25 \pm 6.39^{\mathrm{a}}$ & $30.04 \pm 2.37^{\mathrm{a}}$ \\
PVA85-HA15 film & $10.30 \pm 3.17^{\mathrm{a}}$ & $235.13 \pm 5.23^{\mathrm{b}}$ & $25.27 \pm 1.15^{\mathrm{a}}$ \\
\hline
\end{tabular}


Results express in mean \pm standard deviation. Different letters in the same column indicate significant differences $(p \leq$ 0.05 ) according to the Tukey's test.

\section{CONCLUSIONS}

In this study, we produced a high molecular weight HA from a fermentation process using Streptococcus zooepidemicus in a low-cost sugarcane molasses fermentation medium for use in a blend with polyvinyl alcohol to obtain biodegradable and biocompatible films. All formulations resulted in films with a good appearance that easily removed from the plates without cracking. Thermal stability of these films increased with the addition of HA. Solubility, swelling, water vapor permeability and elongation also increased when HA was added. Among the different HA concentrations, the additions of 5 and $10 \%(\mathrm{w} / \mathrm{w})$ were sufficient to improve the properties of the PVA films. Therefore, the properties obtained from the addition of HA in the PVA films showed that HA is a material that shows promise for use in biomedical applications.

Funding: CAPES-DS-Brazil.

Acknowledgments: The authors wish to thank the Laboratory of Microscopy and Microanalysis (LMEM), the Laboratory of Spectroscopy (ESPEC), the Department of Food Science and Technology from State University of Londrina for the analyses.

Conflicts of Interest: The authors declare no conflict of interest.

\section{REFERENCES}

1. Kogan G, Soltés L, Stern R, Gemeiner P. Hyaluronic acid: a natural biopolymer with a broad range of biomedical and industrial applications. Biotechnol Lett. 2007;29(1):17-25.

2. Chen WYJ, Abatangelo G. Functions of hyaluronan in wound repair. Wound Repair Regen. 1999;7(2):79-89.

3. Collins MN, Birkinshaw C. Hyaluronic acid based scaffolds for tissue engineering-A review. Carbohydr Polym. 2013;92(2):1262-79.

4. Larrañeta E, Henry M, Irwin NJ, Trotter J, Perminova A.A., Donnelly R.F. Synthesis and characterization of hyaluronic acid hydrogels crosslinked using a solvent-free process for potential biomedical applications. Carbohydr Polym. 2018;181:1194-1205.

5. Tchobanian A, Van Oosterwyck H, Fardim P. Polysaccharides for tissue engineering: current landscape and future prospects. Carbohydr Polym. 2019;205:601-25.

6. Liu L, Liu Y, Li J, Du G, Chen J. Microbial production of hyaluronic acid: current state, challenges, and perspectives. Microb Cell Fact. 2011;10(1):99.

7. Yamada T, Kawasaki T. Microbial synthesis of hyaluronan and chitin: new approaches. J Biosci Bioeng. 2005;99(6):521-8.

8. Amado IR, Vázquez JA, Pastrana L, Teixeira JA. Microbial production of hyaluronic acid from agro-industrial byproducts: molasses and corn steep liquor. Biochem Eng J. 2017;117:181-7.

9. Pan NC, Pereira HCB, Silva MDLC, Vasconcelos AFD, Celligoi MAPC. Improvement production of hyaluronic acid by Streptococcus zooepidemicus in sugarcane molasses. Appl Biochem Biotechnol. 2017;182(1):276-93.

10. Pan NC, Vignoli JA, Baldo C, Pereira HCB, Silva RSSF, Celligoi MAPC. Agroindustrial byproducts for the production of hyaluronic acid by Streptococcus zooepidemicus ATCC 39920. Int J Sci Technol Res. 2015;4(04):114-8.

11. Mogoşanu GD, Grumezescu AM. Natural and synthetic polymers for wounds and burns dressing. Int J Pharm. 2014;463(2):127-36.

12. Law N, Doney B, Glover H, Qin Y, Aman ZM, Sercombe TB, et al. Characterisation of hyaluronic acid methylcellulose hydrogels for 3D bioprinting. J Mech Behav Biomed Mater. 2018;77:389-99.

13. Pires AMB, Macedo AC, Eguchi SY, Santana MHA. Microbial production of hyaluronic acid from agricultural resource derivatives. Bioresour Technol. 2010;101(16):6506-9.

14. Oliveira SA, Silva BC, Riegel-Vidotti IC, Urbano A, Faria-Tischer PCS, Tischer CA. Production and characterization of bacterial cellulose membranes with hyaluronic acid from chicken comb. Int J Biol Macromol. 2017;97:642-53.

15. Lewandowska K, Sionkowska A, Grabska S, Kaczmarek B, Michalska M. The miscibility of collagen/hyaluronic acid/chitosan blends investigated in dilute solutions and solids. J Mol Liq. 2016; 220:726-30.

16. Fahmy A, Kamoun EA, El-Eisawy R, El-Fakharany EM, Taha TH, El-Damhougy BK, et al. Poly(vinyl alcohol)hyaluronic acid membranes for wound dressing applications: synthesis and in vitro bio-evaluations. J Braz Chem Soc. 2015;26(7):1466-74.

17. Eskandarinia A, Kefayat A, Rafienia M, Agheb M, Navid S, Ebrahimpour K. Cornstarch-based wound dressing incorporated with hyaluronic acid and propolis: in vitro and in vivo studies. Carbohydr Polym. 2019;216:25-35.

18. Pirinen S, Karvinen J, Tiitu V, Suvanto M, Pakkanen TT. Control of swelling properties of polyvinyl alcohol/hyaluronic acid hydrogels for the encapsulation of chondrocyte cells. J Appl Polym Sci. 2015;132(28):1-6.

19. Kamoun EA, Kenawy ERS, Chen X. A review on polymeric hydrogel membranes for wound dressing applications: PVA-based hydrogel dressings. J Adv Res. 2017;8(3):217-33.

20. Tang X, Alavi S. Recent advances in starch, polyvinyl alcohol based polymer blends, nanocomposites and their 
biodegradability. Carbohydr Polym. 2011;85(1):7-16.

21. Stasko J, Kalninšs M, Dzene A, Tupureina V. Poly(vinyl alcohol) hydrogels. Proc Est Acad Sci. 2009;58(1):63.

22. Kodavaty J, Deshpande AP. Self-assembly and drying assisted microstructural domain formation in poly(vinyl alcohol) and hyaluronic acid gels. Polym Bull. 2017;74(9):3605-17.

23. Ramya KA, Srinivasan R, Deshpande AP. Nonlinear measures and modeling to examine the role of physical and chemical crosslinking in poly(vinyl alcohol)-based crosslinked systems. Rheol Acta. 2018;57(2):181-95.

24. Yilmaz CNC, Pamfil D, Vasile C, Bibire N, Lupuşoru RV, Zamfir CL, et al. Toxicity, biocompatibility, pHresponsiveness and methotrexate release from pva/hyaluronic acid cryogels for psoriasis therapy. Polymers (Basel). 2017;9(4):1-19.

25. Kuchaiyaphum P, Rifai G, Yuuki W, Yamauchi T. Hyaluronic acid-poly(vinyl alcohol) composite cryo-gel for biofunctional material application. Polym Adv Technol. 2019; 30(1):94-100.

26. Kim SH, Hyun K, Moon TS, Mitsumata T, Hong JS, Ahn KH, et al. Morphology-rheology relationship in hyaluronate/poly(vinyl alcohol)/borax polymer blends. Polymer (Guildf). 2005;46(18):7156-63.

27. Ding J, He R, Zhou G, Tang C, Yin C. Multilayered mucoadhesive hydrogel films based on thiolated hyaluronic acid and polyvinylalcohol for insulin delivery. Acta Biomater. 2012;8(10):3643-51.

28. Gontard N, Guilbert S, Cuq J. Edible wheat gluten films: influence of the main process variables on film properties using response surface methodology. J Food Sci. 1992;57(1):190-9.

29. ASTM E96-00. Standard test methods for water vapor transmission of materials. In: ASTM International, editor. Annual book of ASTM. West Conshohocken, PA; 2000.

30. ASTM D882-02. Standard test method for tensile properties of thin plastic sheeting. In: ASTM International, editor. Annual Book of ASTM Standards. West Conshohocken, PA; 2002.

31. R Core Team. R: A language and environment for statistical computing. [Internet]. R Foundation for Statistical Computing. Vienna, Austria; 2019. Available from: https://www.r-project.org/

32. Gallo N, Nasser H, Salvatore L, Natali ML, Campa L, Mahmoud M, et al. Hyaluronic acid for advanced therapies: promises and challenges. Eur Polym J. 2019;117:134-47.

33. Zanin GD, Bunhak ÉJ, dos Santos LF, de Melo EB, Cavalcanti OA. Influence of hyaluronic acid on the formation of isolated poly(vinyl acetate) films for oral solid coatings. J Appl Polym Sci. 2017;134(20):1-10.

34. Li L, Wang N, Jin X, Deng R, Nie S, Sun L, et al. Biodegradable and injectable in situ cross-linking chitosanhyaluronic acid based hydrogels for postoperative adhesion prevention. Biomaterials. 2014; 35(12):3903-17.

35. Calles JA, López-García A, Vallés EM, Palma SD, Diebold Y. Preliminary characterization of dexamethasoneloaded cross-linked hyaluronic acid films for topical ocular therapy. Int J Pharm. 2016; 509(1-2):237-43.

36. Chandran S, Ravichandran V, Chandran S, Chemmanda J, Chandarshekar B. Biosynthesis of PVA encapsulated silver nanoparticles. J Appl Res Technol. 2016;14(5):319-24.

37. Fan L, Yang H, Yang J, Peng M, Hu J. Preparation and characterization of chitosan/gelatin/PVA hydrogel for wound dressings. Carbohydr Polym. 2016;146:427-34.

38. Kwon SS, Kong BJ, Park SN. Physicochemical properties of pH-sensitive hydrogels based on hydroxyethyl cellulose-hyaluronic acid and for applications as transdermal delivery systems for skin lesions. Eur J Pharm Biopharm. 2015;92:146-54.

39. Brandelero RPH, Almeida FM de, Alfaro A. Microestrutura e propriedades de filmes de amido-álcool polivinílicoalginato adicionados de óleos essenciais de copaíba e capim limão (The microstructure and properties of starchpolyvinyl alcohol-alginate films with copaiba and lemongrass oils). Quim Nova. 2015;38(7):910-6.

40. Kanchana S, Arumugam M, Giji S, Balasubramanian T. Isolation, characterization and antioxidant activity of hyaluronic acid from marine bivalve mollusc Amussium pleuronectus (Linnaeus, 1758). Bioact Carbohydrates Diet Fibre. 2013;2(1):1-7.

41. Wu Y. Preparation of low-molecular-weight hyaluronic acid by ozone treatment. Carbohydr Polym. 2012; 89(2):709-12.

42. Reddy KJ, Karunakaran KT. Purification and characterization of hyaluronic acid produced by Streptococcus zooepidemicus. J BioSci Biotech. 2013;2(3):173-9.

43. Haxaire K, Maréchal Y, Milas M, Rinaudo M. Hydration of polysaccharide hyaluronan observed by IR spectrometry. I. Preliminary experiments and band assignments. Biopolym - Biospectroscopy Sect. 2003;72(1):10-20.

44. Jayasekara R, Harding I, Bowater I, Christie GBY, Lonergan GT. Preparation, surface modification and characterisation of solution cast starch PVA blended films. Polym Test. 2004;23(1):17-27.

45. Gilli R, Kacuráková M, Mathlouthi M, Navarini L, Paoletti S. FTIR studies of sodium hyaluronate and its oligomers in the amorphous solid phase and in aqueous solution. Carbohydr Res. 1994;263(2):315-26.

46. Chen J-P, Cheng T-H. Preparation and evaluation of thermo-reversible copolymer hydrogels containing chitosan and hyaluronic acid as injectable cell carriers. Polymer (Guildf). 2009;50(1):107-16.

47. Lewandowska K, Sionkowska A, Grabska S, Kaczmarek B. Surface and thermal properties of collagen/hyaluronic acid blends containing chitosan. Int J Biol Macromol. 2016;92:371-6.

48. Tubbs RK, Ting KW. Thermal properties of polyvinyl alcohol. In: Finch CA, editor. Polyvinyl alcohol - Developments. Chichester: John Wiley; 1973. p. 167-82.

49. Sin LT, Rahman WAWA, Rahmat AR, Mokhtar M. Determination of thermal stability and activation energy of polyvinyl alcohol-cassava starch blends. Carbohydr Polym. 2011;83(1):303-5.

50. Jang J, Lee DK. Plasticizer effect on the melting and crystallization behavior of polyvinyl alcohol. Polymer (Guildf). 
2003;44(26):8139-46.

51. Othman N, Azahari NA, Ismail $\mathrm{H}$. Thermal properties of polyvinyl alcohol (PVOH)/corn starch blend film. Malaysian Polym J. 2011;6(6):147-54.

52. Wang R, Wang Q, Li L. Evaporation behaviour of water and its plasticizing effect in modified poly(vinyl alcohol) systems. Polym Int. 2003;52(12):1820-26.

53. Pereira VA, de Arruda INQ, Stefani R. Active chitosan/PVA films with anthocyanins from Brassica oleraceae (Red Cabbage) as Time-Temperature Indicators for application in intelligent food packaging. Food Hydrocoll. 2015;43:180-88.

54. Lewandowska K. Miscibility and thermal stability of poly(vinyl alcohol)/chitosan mixtures. Thermochim Acta. 2009;493(1-2):42-8.

55. Sionkowska A, Kaczmarek B, Lewandowska K, Grabska S, Pokrywczyńska M, Kloskowski T, et al. 3D composites based on the blends of chitosan and collagen with the addition of hyaluronic acid. Int J Biol Macromol. 2016;89:4428.

56. Maria TMC, de Carvalho RA, Sobral PJA, Habitante AMBQ, Solorza-Feria J. The effect of the degree of hydrolysis of the PVA and the plasticizer concentration on the color, opacity, and thermal and mechanical properties of films based on PVA and gelatin blends. J Food Eng. 2008;87(2):191-9.

57. Collins MN, Birkinshaw C. Physical properties of crosslinked hyaluronic acid hydrogels. J Mater Sci Mater Med. 2008;19(11):3335-43.

58. Sgorla D, Almeida A, Azevedo C, Bunhak ÿlcio J, Sarmento B, Cavalcanti OA. Development and characterization of crosslinked hyaluronic acid polymeric films for use in coating processes. Int J Pharm. 2016;511(1):380-389.

59. Briscoe B, Luckham P, Zhu S. The effects of hydrogen bonding upon the viscosity of aqueous poly(vinyl alcohol) solutions. Polymer (Guildf). 2000;41(10):3851-60.

60. Li Z, Ramay HR, Hauch KD, Xiao D, Zhang M. Chitosan-alginate hybrid scaffolds for bone tissue engineering. Biomaterials. 2005;26(18):3919-28.

61. Shanmugasundaram N, Ravichandran P, Neelakanta Reddy P, Ramamurty N, Pal S, Panduranga Rao K. Collagen-chitosan polymeric scaffolds for the in vitro culture of human epidermoid carcinoma cells. Biomaterials. 2001;22(14):1943-51.

62. Bertuzzi MA, Castro Vidaurre EF, Armada M, Gottifredi JC. Water vapor permeability of edible starch based films. J Food Eng. 2007;80(3):972-8.

63. $\mathrm{Xu} \mathrm{H}, \mathrm{Ma}$ L, Shi H, Gao C, Han C. Chitosan-hyaluronic acid hybrid film as a novel wound dressing: in vitro and in vivo studies. Polym Adv Technol. 2007;18:869-75.

2020 by the authors. Submitted for possible open access publication under the terms and conditions of the Creative Commons Attribution (CC BY NC) license (https://creativecommons.org/licenses/by-nc/4.0/). 